\title{
ANALYSIS OF A 870 m DEEP TEMPERATURE PROFILE
}

\section{AT DOME C}

\author{
by \\ Catherine Ritz, Louis Lliboutry and Claude Rado \\ (Laboratoire de Glaciologie et Géophysique de l'Environnement, 2 rue Très-Cloîtres, \\ 38031 Grenoble Cedex, France)
}

\section{ABSTRACT}

The French $870 \mathrm{~m}$ deep temperature profile gives us temperature differences with an accuracy of $0.01 \mathrm{deg}$ (to obtain such an accuracy, the sensors must be applied against the walls of the bore hole). The error on the vertical gradient $T$ ' cannot be lessened by weighted running means. Thus, only a mean value of its derivative $T$ " can be reached.

Data have been analysed by assuming a twodimensional flow over a plane horizontal bedrock. As a first step, the steady state at an ice divide has been calculated by solving the complete set of equations. The vertical strain-rate is a constant over two-thirds of the ice sheet. It appears that, at Dome $C$, sliding and no-sliding solutions are plausible, as well as cyclic oscillations between them. Next, the temperature response of the ice sheet to an impulse for the surface temperature has been computed, and convolved with surface palaeotemperatures deduced from the $18_{0}$ profile, to obtain the time derivative $\dot{T}$.

Mean values of $T^{\prime}, T^{\prime \prime}$ and $\dot{T}^{\prime}$ allow an estimation of the vertical velocity, which is much smaller than the balance one. Therefore, the ice sheet has thickened by 200 to $280 \mathrm{~m}$ during the last $10 \mathrm{ka}$.

\section{INTRODUCTION}

After coring at Dome $\mathrm{C}$, Antarctica, to a depth of $905 \mathrm{~m}$ in 1977-78 (Lorius and Donnou 1978), temperatures were measured in the bore hole at 15 points. A more detailed temperature profile was obtained in 1978-79. Both will be analysed in this paper. Since probably, during the years to come, many temperature profiles in polar ice sheets will be obtained, still wi thout accurate surface velocities or ages, it was worth examining all the information which may be retrieved from such temperature profiles.

Throughout this article the $x$-axis will be put at the ice-bedrock interface, in the direction of flow, and the $z$-axis upwards. Let $u$ and $w$ be the corresponding velocities and $H$ the ice-sheet thickness, after replacing the firn by an ice layer of the same weight. Subscripts $s$ denote surface values, subscripts b bottom ones.

The classical way of handling this problem is to set down a simple analytical expression for $w(x, z)$, involving one or two unknown parameters, and to compute the corresponding temperature profile $T(z)$. For instance:

$$
\begin{aligned}
w & =w_{s} z / H & & (\text { Rob in 1955), } \\
\partial w / \partial z & =w_{s} u(x, z) /(H U) & & (\text { Budd and others 1970), } \\
w & =w_{s} u(x, z) z /(H U) & & \text { (Budd and others 1973). }
\end{aligned}
$$

In the very cold upper layers, $u=u(x)$ only, whence $\partial^{2} u / \partial x \partial z=-\partial^{2} w / \partial z^{2}=0$, and

$$
w=w_{s}(z-h) /(H-h)
$$

(Dansgaard and Johnsen 1969, Hammer and others 1978).

The parameter $h$ in expression (1) has been estimated by L1iboutry (1979), assuming $u>>w$ and a bottom below freezing point. For a cold ice sheet of gently varying thickness, Lliboutry's formula (equation 51 in the above-mentioned paper) is:

$$
\frac{h}{H}=\frac{A+r u_{s}(\alpha-\beta)}{r\left[A+u_{s}(\alpha-\beta)\right]},
$$

A being the accumulation (in equivalent height of $i c e), u$ the surface forward velocity, $\alpha$ and $\beta$ the slopes of surface and bedrock, respectively, and $r=n+1+Q G H /\left(R T^{2}\right)$ ( $n$ is the exponent in Glen's creep law $(n=3)$, $Q$ the activation energy for ice creep, $R$ the gas constant, and $G$ the geothermal gradient in stagnant ice $\left.\left(G \cong 0.02 \mathrm{deg} \mathrm{m}^{-1}\right)\right)$.

When $\alpha=\beta=0$, this formula reduces to $h \approx H / r$. For Dome $C, r \approx 10.8$. Unfortunately, in our case, the bore hole is at an ice divide, where $w$ and $u$ are of the same order of magnitude, and normally this relation does not hold. Thus, a complete calculation of the coupled fields of velocities and temperatures must be done.

Near an ice divide, the horizontal advection of heat, its horizontal diffusion, and the viscous heat generation are negligible. With $C_{0}$ denoting the heat capacity per unit volume, $K$ the thermal conductivity, primes denoting derivatives with respect to $z$, and overdots time derivatives, the heat equation is:

$$
\left(K T^{\prime}\right)^{\prime}=C_{\rho}\left(w T^{\prime}+\dot{T}\right) \text {. }
$$


Ritz and others: $870 \mathrm{~m}$ deep temperature profile at Dome $C$

The first objective, then, is to deduce $T^{\prime}(z)$ from the field measurements. We shall see that only a constant, mean value of $T$ " in the bore hole can be confidently reached.

Next, a simplified calculation of both temperature and velocity fields, in the steady case, will be performed. It will give us an estimate of $h$, and of the bottom temperature.

Third, using relations (1) and (3), the temperature response of the ice sheet to a step function in Ts will be calculated. A time derivative will give us the response to a Dirac impulse for $T_{S}$, i.e. the impulse response $R(z, t)$. Since past surface temperatures $T_{s}(t)$ are known from ${ }^{18} 0$ measurements, the transient profile of temperatures can then be calculated by convolving $T_{S}(t)$ and $R(z, t)$, whence $\dot{T}$.

Lastly, the actual vertical velocity can be deduced from relation (3). Since the mean accumulation $A$ during recent centuries is known, the change in thickness of the ice sheet will ensue:

$$
\dot{H}=A+W_{S} \text {. }
$$

FIELD TEMPERATURE PROFILE AND ITS DERIVATIVES

Temperature sensors were VECO 31 A52 thermistors, embedded within copper bodies, in order to make selfwarming during measurements negligible. A device pressed the copper bodies against the walls of the bore hole, and two disks of silicone rubber isolated the portion of hole where the measurement was made.

Below $330 \mathrm{~m}$, the air temperature in this closed chamber was also measured. The difference fluctuates between 0.20 and $0.27 \mathrm{deg}$. Since the objective is to measure temperature differences of about 0.08 deg for two points $10 \mathrm{~m}$ apart, the habitual method of merely measuring air temperatures in the bore hole must be excluded.

All field data are given in Table 1 . Below $650 \mathrm{~m}$, only a few points, each $50 \mathrm{~m}$, could be obtained, because of the fast closure of the empty bore hole. The very constant difference between the temperatures given by each sensor shows that temperature intervals are accurate to $0.01 \mathrm{deg}$. The inaccuracy comes principally from the field voltmeter which was used (Schlumberger 7040). Calibration was done in Grenoble with a more precise one (DANA 5330, accuracy $10^{-5}$ instead of $20 \times 10^{-5}$ ) and a standard of temperature Tinsley 5187 SA. Although this standard has a theoretical accuracy of $0.001 \mathrm{deg}$, constant differences of 0.01 deg between sensors $C$ and $E$, and of $0.04 \mathrm{deg}$ between sensors $C$ and $A$ were observed in the field.

Values of $T^{\prime}(z)$ are given on Figures 1 and 2 . In order to suppress noise, temperature values $10 \mathrm{~m}$ apart were smoothed by weighted running means (of 5 or 15 terms) which are almost perfect low-pass filters:

$$
\begin{aligned}
\overline{\mathrm{T}}_{i}= & \frac{1}{9}\left[\mathrm{~T}_{i-2}+2 \mathrm{~T}_{i-1}+3 \mathrm{~T}_{i}+2 \mathrm{~T}_{i+1}+\mathrm{T}_{i+2}\right] \\
\overline{\mathrm{T}}_{i}= & \frac{1}{320}\left[-3 \mathrm{~T}_{i-7}-6 \mathrm{~T}_{i-6}-5 \mathrm{~T}_{i-5}+3 \mathrm{~T}_{i-4}+21 \mathrm{~T}_{i-3}+\right. \\
& +46 \mathrm{~T}_{i-2}+67 \mathrm{~T}_{j-1}+74 \mathrm{~T}_{i}+67 \mathrm{~T}_{i+1}+46 \mathrm{~T}_{i+2}+ \\
& \left.+21 \mathrm{~T}_{i+3}+3 \mathrm{~T}_{j+4}-5 \mathrm{~T}_{i+5}-6 \mathrm{~T}_{i+6}-3 \mathrm{~T}_{i+7}\right] .
\end{aligned}
$$

Oscillations of 'T' by a few per cent, with a wavelength of about $100 \mathrm{~m}$, were found, identical in both cases. On Figure 2, the temperatures every $20 \mathrm{~m}$, for even and odd decametres, have been handled separately. Weighted means over five successive terms then give oscillations which are in phase below $400 \mathrm{~m}$ and opposite above. Thus these oscillations, and the oscillating value for $T$ " which may be deduced, have no phys-

TABLE I. MEASURED TEMPERATURES IN THE DOME $\mathrm{C}$ BORE HOLE $\left({ }^{\circ} \mathrm{C}\right)$

$\begin{array}{ccccccc}\text { Depth } & \text { Jan } 78 & 10-22 & \text { Dec } & 78 & 1-6 & \text { Jan } 79 \\ (\mathrm{~m}) & \left({ }^{\circ} \mathrm{C}\right) & \mathrm{E} & \mathrm{C} & \mathrm{A} & \text { air }\end{array}$

5 $-55.21 \quad-55.14$

5
10

10

20

20
25

30

35

40
50

50

60

70
80

90

100

110

120

125

130

140

145

150

160

170

180

190

195

200

210
220

230
240

250

260

270

280

290

300

310

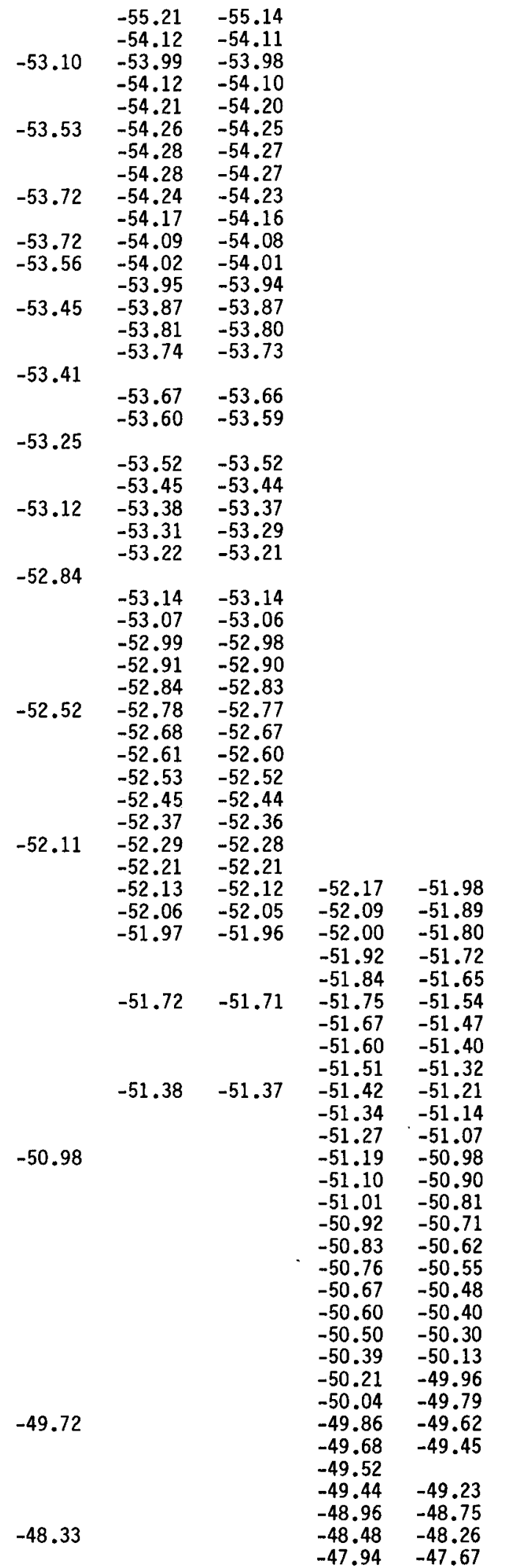




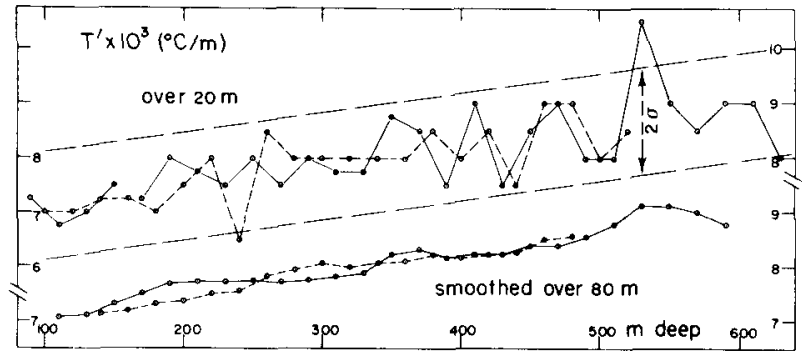

Fig.1. Temperature gradient over $20 \mathrm{~m}$, as measured at Dome $C$ bore hole. Below: running weighted means of five values. Solid line: at odd decametres; dashed line: at even decametres.

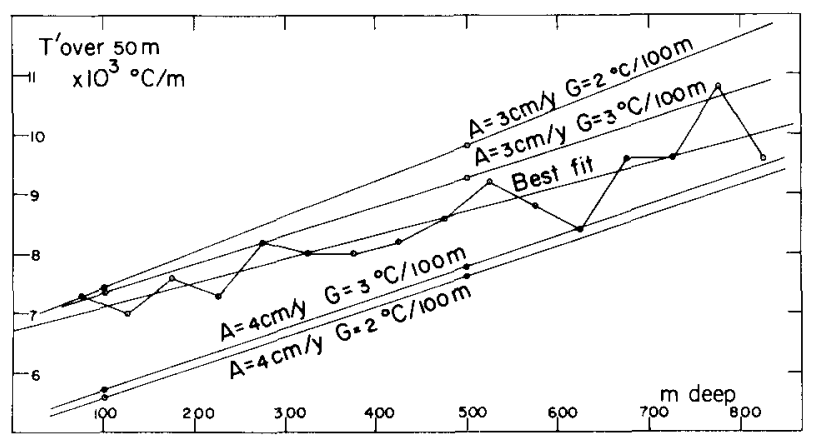

Fig.2. Temperature gradients over $50 \mathrm{~m}$, compared with theoretical values for the steady state. $A$ : accumulation; $G$ : geothermal gradient in motionless ice.

ical meaning. (We hope this misadventure will make geophysicists who work only with smoothed data cautious!)

The general trend for $T^{\prime}$ is linear. A leastsquare fit gives $T^{\prime \prime}=(3.63 \pm 0.2) \times 10^{-6} \mathrm{deg} \mathrm{m}^{-2}$ between 100 and 520 or $630 \mathrm{~m}$ (Fig.1), and $T^{\prime \prime}=4.0 \times 10^{-6} \mathrm{deg} \mathrm{m}^{-2}$ between 75 and $825 \mathrm{~m}$ (Fig.2).

CALCULATION OF THEORETICAL VELOCITIES AND TEMPERATURES AT AN ICE DIVIDE IN THE STEADY CASE

We assume the problem to be two-dimensional, with $x=0$ as symmetry axis. This assumption is realistic, since Dome $C$ is an elongated shoulder rather than a true dome. The bedrock is assumed to be a horizontal plane $(z=0)$, since its slope remains within the range $(-0.1$ to +0.1$)$, and we are only interested in the upper layers of the ice sheet.

The main unknown is ice rheology, since it depends strongly on ice fabrics. In this calculation we adopt Glen s law for tertiary creep of ice, when the peculiar ice fabric, with four maxima of c-axis (as found in active ice near the melting point), has been formed (Duval 1981). Nevertheless, to avoid numerical instability, a Newtonian viscous term (which may indeed exist) has been added. The temperature dependence is introduced by an Arrhenius factor the same for both terms, although the apparent activation energy $Q$ is known to increase above $-10^{\circ} \mathrm{C}$. The viscosity $n$ is then given by:

$\frac{1}{\eta}=\left[\phi+B\left(\frac{\sigma_{x}-\sigma_{z}}{2}\right)^{2}+\tau_{x z}^{2}\right] \cdot \exp \left[\frac{Q}{R}\left(\frac{1}{T_{f}}-\frac{1}{T}\right)\right]$, where $T_{f}$ is the temperature at the melting point

$$
T_{f}=273.2-\mu(H-z),
$$

$\mu$ being $1 / 1503 \mathrm{deg} \mathrm{m}^{-1}$.

According to Duval (1981), $\mathrm{B}=0.1 \mathrm{bar}^{-3} \mathrm{a}^{-1}$. A value $Q=60 \mathrm{~kJ} \mathrm{~mol}^{-1}$ has been adopted, which is nearer to Paterson's (1977) field value (54 $\mathrm{kJ} \mathrm{mol}^{-1}$ ) than to Homer and Glen's (1978) experimental one $\left(75 \mathrm{~kJ} \mathrm{~mol}^{-1}\right)$. As for the Newtonian fluidity $\phi$, it should be less than $0.01 \mathrm{bar}^{-1} \mathrm{a}^{-1}$ in order to become negligible in Duval's laboratory experiments.

Boundary conditions are: at the surface, no stresses against the surface, a uniform velocity $w_{S}$ $=-A$, and a constant temperature $T_{s}$, and, at the bottom, either cold conditions $\left(T_{b}<T_{f}\right)$, the thermal gradient $T^{\prime}$ having a given value $G$, with no sliding $\left(u_{b}=w_{b}=0\right)$, or temperate conditions $\left(T_{b}=T_{f}\right)$, with $w_{b}$ given by the energy balance, and $u_{b}$ by the following stiding $1 \mathrm{aw}$ :

$$
u_{b}=k_{1}\left(\tau_{x z}\right)_{b}+k_{3}\left(\tau_{x z}\right)_{b}^{3}
$$

This law would be found on a smooth sine profile, without ice-bedrock separation. The first term accounts for the melting-regelation process, and for the Newtonian viscosity; the second one accounts for the plastic deformation.

Lateral boundary conditions are the most difficult to introduce. There do not exist regions on both sides where stresses could be considered as independent of $x$. A large number of mesh points along a horizontal would lead to huge calculations on a big computer, which our very crude rheological law and two-dimensional assumption do not deserve. Moreover, we are interested in the values for $x=0$.only.

Thus, only three horizontal mesh points are taken, which means that all functions are approximated by odd or even polynomials in $x$ with two terms only. Notwithstanding, in order to obtain the finite difference equivalent (in $x$ ) of the generalized biharmonic equation, the mean stress $\bar{\sigma}=\left(\sigma_{x}+\sigma_{z}\right) / 2$ must be approximated by a polynomial with three terms. Let us write, then (q denoting the stream function):

$$
\begin{aligned}
& q(x, z)=x f_{0}+\frac{x^{3}}{6} f_{2}, \\
& T(x, z)=T_{f}+\theta_{0}+\frac{x^{2}}{2} \theta_{2}, \\
& n(x, z)=n_{0}+\frac{x^{2}}{2} n_{2}, \\
& \bar{\sigma}(x, z)=\bar{\sigma}_{0}+\frac{x^{2}}{2} \bar{\sigma}_{2}+\frac{x^{4}}{24} \bar{\sigma}_{4},
\end{aligned}
$$

where the $f_{i}, \theta_{i}, \eta_{i}, \bar{\sigma}_{i}$ are functions of $z$. The deviatoric stresses are then:

$$
\begin{aligned}
\frac{\sigma_{x}-\sigma_{z}}{2}=2 n \frac{\partial^{2}}{\partial x \partial z}=2 \eta_{0}^{\prime} f_{0}^{\prime} & +x^{2}\left(n_{0} f_{2}^{\prime}+n_{2} f_{0}^{\prime}\right)+\frac{x^{4}}{2} n_{2} f_{2}^{\prime}, \\
\tau_{x z}=n\left(\frac{\partial^{2} q}{\partial z^{2}}-\frac{\partial^{2} q}{\partial x^{2}}\right)= & x_{0}\left(f_{0}^{\prime \prime}-f_{2}\right)+ \\
& +\frac{x^{3}}{6}\left[n_{0} f_{2}^{\prime \prime}+3 n_{2}\left(f_{0}^{\prime \prime}-f_{2}\right)\right]+ \\
& +\frac{x^{5}}{12} n_{2} f_{2}^{\prime \prime} .
\end{aligned}
$$


Equating in the equilibrium conditions (where og denotes the specific weight of ice):

$$
\begin{aligned}
& \frac{\partial}{\partial x}\left[\bar{\sigma}+\frac{\sigma_{x}-\sigma_{z}}{2}\right]+\frac{\partial \tau x z}{\partial z}=0, \\
& \frac{\partial \tau x z}{\partial x}+\frac{\partial}{\partial z}\left[\bar{\sigma}-\frac{\sigma_{x}-\sigma_{z}}{2}\right]=\rho g,
\end{aligned}
$$

coefficients in like powers of $x$, the following five differential equations in $z$ only are obtained:

$$
\bar{\sigma}_{0}^{\prime}-2\left(n_{0} f_{0}^{\prime}\right)^{\prime}+n_{0}\left(f_{0}^{\prime \prime}-f_{2}\right)=\rho g
$$

(This first relation, which would enable a computation of $\sigma 0$, hence of $\sigma_{x}$ and $\sigma_{z}$, is useless for our

$\bar{\sigma}_{2}+2\left(n_{0} f_{2}^{\prime}+n_{2} f_{0}^{\prime}\right)+\left(n_{0}\left(f_{0}^{\prime \prime}-f_{2}\right)\right)^{\prime}=0$,

$\bar{\sigma}_{2}^{\prime}-2\left(n_{0} f_{2}^{\prime}+n_{2} f_{0}^{\prime}\right)+n_{0} f_{2}^{\prime \prime}+3 n_{2}\left(f_{0}^{\prime \prime}-f_{2}\right)=0$,

$\vec{\sigma}_{4}+12 n_{2} f_{2}^{\prime}+\left(n_{0} f_{2}^{\prime \prime}+3 n_{2}\left(f_{0}^{\prime \prime}-f_{2}\right)\right)^{\prime}=0$,

$\vec{\sigma}_{4}^{\prime}-12\left(n_{2} f_{2}^{\prime}\right)^{\prime}+10 \pi_{2} f_{2}^{\prime \prime}=0$.

By eliminating $\bar{o}_{2}$ and $\bar{a}_{4}$, two coupled ordinary differential equations of the fourth order in $f_{0}$ and $f_{2}$ are found.

In a similar way, the heat equation in the steady case:

$\kappa\left(\partial^{2} \theta / \partial x^{2}+\partial^{2} \theta / \partial z^{2}\right)-u \partial \theta / \partial x-w(\partial \theta / \partial z+\mu)=0$,

where $k=K / C_{\rho}$ is the thermal diffusivity, affords two coupled ordinary differential equations of the second order in $\theta_{0}$ and $\theta_{2}$. Lastly, the viscosity is deduced from Equation (5), which becomes, by putting

$$
\begin{aligned}
E_{0} & =\exp \left[-\frac{Q \theta_{0}}{R T_{f}\left(T_{f}+\theta_{0}\right)}\right] \\
E_{0}\left[1-\frac{x^{2}}{2} \frac{Q \theta_{2}}{R\left(T_{f}+\theta_{0}\right)^{2}}\right] & =\phi \eta+4 B n^{3}\left(\varepsilon_{x x}^{2}+\varepsilon_{x z}^{2}\right) .
\end{aligned}
$$

Our procedure computes successively $\theta_{0}, \theta_{2}, n_{0}$, $n_{2}, f_{2}, f_{0}$, according to the following equations:

$$
\begin{aligned}
& \kappa \theta_{0}^{\prime \prime}+f_{0}\left(\theta_{0}^{\prime}+\mu\right)=-\kappa \theta_{2} \\
& \kappa \theta_{2}^{\prime \prime}+f_{0} \theta_{2}^{\prime}-2 f_{0}^{\prime} \theta_{2}=-f_{2}\left(\theta_{0}^{\prime}+\mu\right) \\
& 4 B f_{0}^{\prime 2} n_{0}^{3}+\phi \eta_{0}=E_{0} \\
& {\left[12 B n_{0}^{2} f_{0}^{\prime 2}+\phi\right] \eta_{2}=-2 B n_{0}^{3}\left[4 f_{0}^{\prime} f_{2}^{\prime}+\left(f_{0}^{\prime \prime}-f_{2}\right)^{2}\right]-\frac{Q \theta_{2}}{R\left(T_{f_{0}}+\theta_{0}\right)^{2}} E_{0}} \\
& \left(n_{0} f_{2}^{\prime \prime}\right) "+11 n_{2} f_{2}^{\prime \prime}+18 n_{2}^{\prime} f_{2}^{\prime}-3 n_{2}^{\prime \prime} f_{2}=-3\left(n_{2} f_{0}^{\prime \prime}\right) " \\
& \left(n_{0} f_{0}^{\prime \prime}\right) "+\eta_{2} f_{0}^{\prime \prime}+4 n_{2}^{\prime} f_{0}^{\prime}=-2\left(n_{0} f_{2}^{\prime}\right)^{\prime}+\left(n_{0}^{\prime \prime}-3 n_{2}\right) f_{2}
\end{aligned}
$$

The boundary conditions at the surface are:

$$
\begin{array}{lll}
f_{0}(H)=A & f_{2}(H)=0 & \theta_{0}(H)=\theta_{s} \\
f_{0}^{\prime \prime}(H)=0 & f_{2}^{\prime \prime}(H)=0 & \theta_{2}(H)=0 .
\end{array}
$$

For a cold bottom:

$$
\begin{array}{lll}
f_{0}(0)=0 & f_{2}(0)=0 & \theta_{0}^{\prime}(0)=-(G+\mu) \\
f_{0}^{\prime}(0)=0 & f_{2}^{\prime}(0)=0 & \theta_{2}^{\prime}(0)=0 .
\end{array}
$$

For a temperate bottom, $L$ denoting the latent heat of ice:

$$
\begin{array}{ll}
\theta_{0}(0)=0 & f_{0}(0)=(K / L \rho)\left[G+\mu+\theta_{0}^{\prime}(0)\right] \\
\theta_{2}(0)=0 & f_{2}(0)=(K / L \rho) \theta_{2}^{\prime}(0) .
\end{array}
$$

As starting values, the following ones, which satisfy the boundary conditions for the cold bottom case, but not all equations (15), are adopted:

$$
\theta_{2}=\eta_{2}=f_{2}=0 \quad f_{0}=3 A\left[\frac{z^{2}}{2 H^{2}}-\frac{z^{3}}{6 H^{3}}\right] \text {. }
$$

If, during the computation, the temperature at the bottom reaches the melting point, the procedure switches to the one for a temperate bottom, and vice versa.

RESULTS FROM THE NUMERICAL MODEL

Computation was done by a second-order finite-difference method with $\mathrm{H}=3400$, $k=36.8-0.09 \theta \mathrm{m}^{2} \mathrm{a}^{-1}, \theta_{\mathrm{s}}=-53.7^{\circ} \mathrm{C}$ (the actual surface temperature), $-55^{\circ} \mathrm{C}$ or $-60^{\circ} \mathrm{C}$, and several realistic values for $\phi, A, G, k_{1}, k_{3}$. Convergence was obtained after about ten iterations when $\phi$ was not too small. Velocities and temperatures are insensitive to the adopted value for $\phi$, and to the value of $k_{3}$ in the range $0.2-2 \mathrm{~m} \mathrm{a}^{-1} \mathrm{bar}^{-3}$ (the term $k_{3} b^{3}$ is totally negligible). The influence of $k_{1}$ on the temperatures is also negligible. We give our results for $k_{1}=0.6 \mathrm{~m} \mathrm{a}^{-1} \mathrm{bar}^{-1}$.

Three cases may occur, which are summarized on Figure 3. Either the bottom is temperate $(T)$, or it is cold (C), or no steady state exists $(0)$. In the last case, temperate bottom conditions lead to a cold bottom, and the reverse, indefinitely. Our interpretation is that the regime should be cyclical: sliding

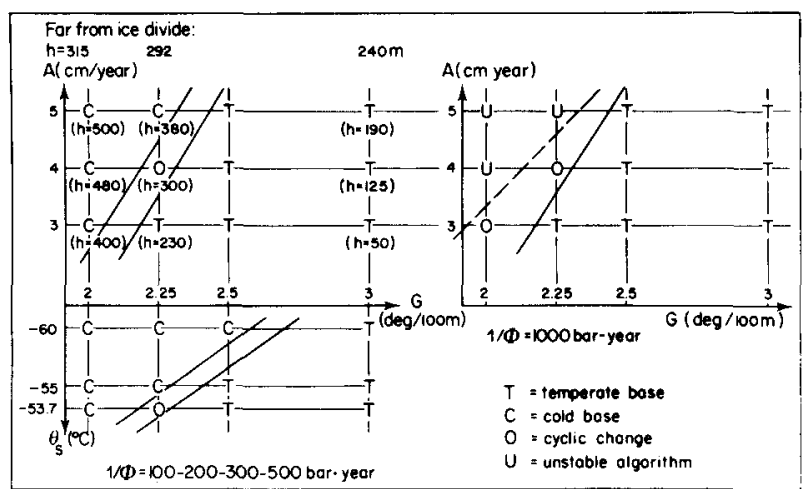

Fig.3. Results from numerical simulation (see text). Situation at the bottom, in the steady state, for different values of the accumulation $A$ (in metres of $i(c)$ ), of the surface temperature $\theta_{s}$, and of the geothermal gradient $G$. Below each case, in brackets, value of $h$ in Equation (1). Above, values of $h$ given by (2), far from an ice divide. 
allows more advection of cold towards the bottom, and freezing. No-sliding lessens this advection, and then the melting point is reached and sliding appears.

Theoretical values of $T^{\prime}(z)$ for the steady state are given in Figure 2. They are more sensitive to accumulation than to the geothermal flux. In any case the steady state value for $T^{\prime \prime}$ is larger than the. actual one, which shows that the transient term $\dot{T}$ in Equation (3) cannot be neglected.

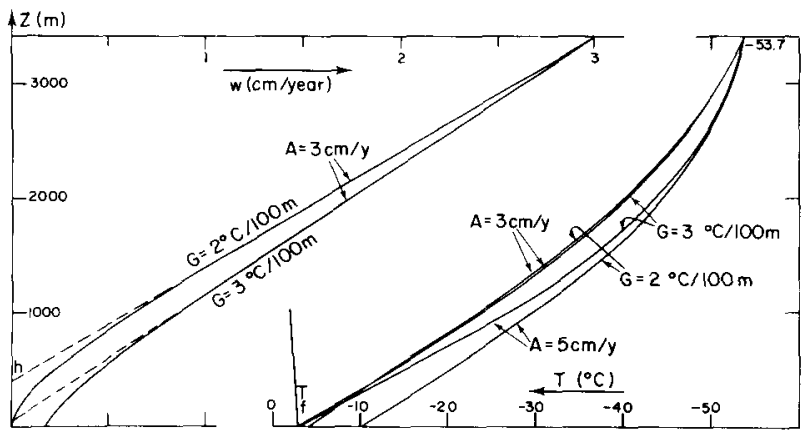

Fig.4. Left: vertical velocity w. Right: theoretical temperature profiles (steady state).

$T(z)$ and $\theta(z)$ are plotted in Figure 4 . It appears that Dansgaard and Johnsen's analytical expression for $w$ (Equation (2)) is valid for the upper two thirds of the ice sheet. Values of parameter $h$ will be found in Figure 3 (as well as those calculated from Lliboutry's formula which, as has already been said, is not valid at an ice divide).

\section{CALCULATION OF THE TRANSIENT TERM IN THE TEMPERATURE PROFILE}

Within the firn layer of a real ice sheet, changes in the surface temperature propagate downwards owing to thermal diffusion much more than to solid advection. Since at $10 \mathrm{~m}$ depth a mean annual temperature is reached, at the firn-ice limit, about $100 \mathrm{~m}$ deep, a mean secular temperature should be reached. Now, (at Dome C) about 2 ka are needed for firn to reach this depth.

The thermal diffusivity of snow or firn, whatever $i$ ts density, is about $13 \mathrm{~m}^{2} \mathrm{a}^{-1}$, one third of its value for ice (Lliboutry 1964: 394). Nevertheless, it has been measured under conditions when heat transit through the air phase comes only from molecular diffusion, ignoring any vertical motion of the air within the neve caused by atmospheric pressure changes or gusts of wind. Thus, the actual thermal diffusivity of firn is larger, and unknown.

For these reasons, it is impossible to-day to calculate transient temperature profiles within the firn, and we shall calculate transient temperatures below $100 \mathrm{~m}$ depth only. The precise phase lag between temperature oscillations at $100 \mathrm{~m}$ depth and at the surface (said to be of the order of one century) is unknown, as well as their damping. Only mean temperatures over one millenium or more will be significant.

At this large time scale, our model, in which the firn is replaced by an ice layer of the same weight, may be retained. To study how a perturbation in the surface temperature propagates downward with time, the values $A=37 \mathrm{~mm} \mathrm{a}^{-1}$ (the present accumulation). $G=0.0225 \mathrm{deg} \mathrm{m}^{-1}$ and $1 / \phi=300$ bar a were adopted. This is a limiting case, where both conditions $T_{b}=T_{f}$ and $w_{b}=0$ are satisfied. The corresponding value of $h$ is $300 \mathrm{~m}$, approximately the one given by Lliboutry's formula.

The perturbation in the temperature is assumed not to change the flow, and so only remains a problem of heat diffusion in a moving medium. It was solved by a method indicated by Douglas and Jones (Remson and others 1971:98-101), which is a variant of the

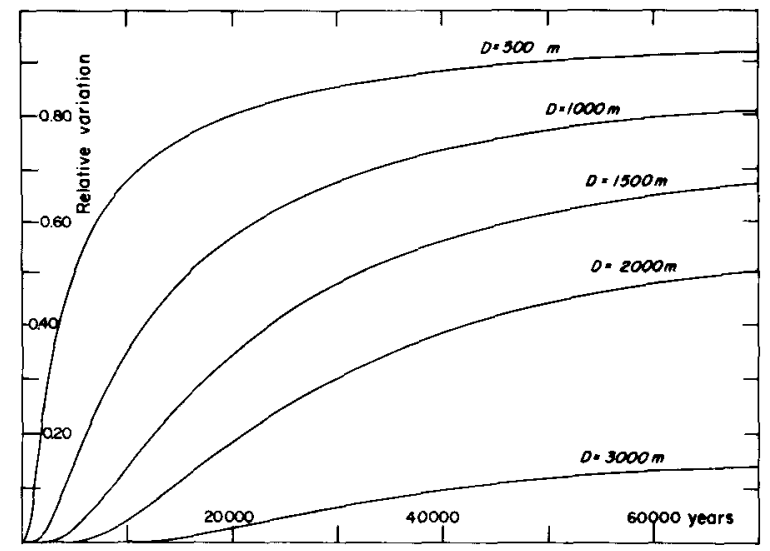

Fig.5. Response of the temperature within the ice sheet to a step at time zero, as temperature variation at the surface. A: $3.7 \mathrm{~cm} \mathrm{a}^{-1}$, $\mathrm{G}: 0.0225 \mathrm{deg} \mathrm{m}^{-1}$.

Crank-Nicholson method. Our program was tested by computing the temperatures in the case handled by Whillans (1978) (although he adopts $h=0$, the difference remains negligible in the upper layers). our results are given in Figure 5 . They show that, in the case of Dome $C$, the ice sheet still reacts to surface temperature changes during the Riss-Wüm intergl acial.

After calculating the impulsive response, it was convolved with palaeotemperatures drawn from $18_{0}$ data (Lorius and others 1979). Their time scale is drawn from the rough expression (1) for the vertical velocity, with $h=0, w_{s}=-A$, and $A=37 \mathrm{~mm} \mathrm{a}^{-1}$ down to $381 \mathrm{~m}$ depth (equivalent to $10.921 \mathrm{ka} \mathrm{BP}$ ), A decreasing linearly from 37 to 27.8 between 381 and $510 \mathrm{~m}$ depth, and $A=27.8 \mathrm{~mm} a^{-1}$ from 510 to $873 \cdot \mathrm{m}$ depth (equivalent to from 15.516 to $31.956 \mathrm{ka} \mathrm{BP}$ ).

This time scale may be improved by using our better calculation, but, since it has been fitted on well-dated climatic accidents, the correction would be negligible. In order to avoid any spurious effect, all the measured palaeotemperatures were used, not smoothed values. An important correction was made to account for the change in the ${ }^{18} 0$. content of oceans during the glacial epoch.

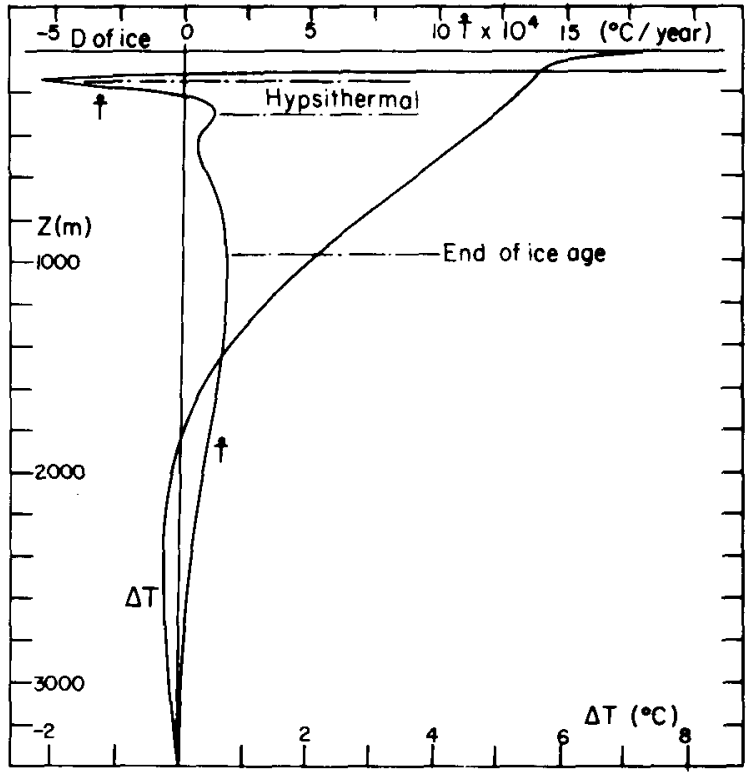

Fig.6. Theoretical values of the present temperature variation $\Delta T$ and its time derivative $\dot{T}$, as drawn from ${ }^{180}$ palaeotemperatures. 
Results are given on Figure 6 . The theoretical $\dot{T}(z)$ has important fluctuations within the studied range of depth. The negative spike $\left(-6.9 \times 10^{-4}\right.$ deg $\left.a^{-1}\right)$ at $150 \mathrm{~m}$ depth corresponds to the ending of the hypsithermal, the first maximum $\left(1.3 \times 10^{-4} \mathrm{deg}^{-1}\right)$ to its beginning, and the broader one $\left(2.0 \times 10^{-4} \mathrm{deg} \mathrm{a}^{-1}\right)$ around $1000 \mathrm{~m}$ depth to the warming which ended the last ice age. The mean value of $\dot{T}(z)$ between 100 and $800 \mathrm{~m}$ depth (including all the negative spike) is found to be $0.38 \times 10^{-4} \mathrm{deg}^{-1}$. The mean value of $\dot{T}(z)$ between $230 \mathrm{~m}$ (when it becomes positive) and $800 \mathrm{~m}$ is found to be $1.02 \times 10^{-4} \mathrm{deg} \mathrm{a}^{-1}$.

\section{ESTIMATION OF $\dot{H}$, AND DISCUSSION}

The mean value of $\dot{T}(z)$ in the bore hole is very poorly known, as a consequence of the strong variability of $\dot{T}(z)$ near the surface. The two abovementioned values may be considered as lower and upper bounds. Let us use now relation (4), with $\kappa=41.5 \mathrm{~m}^{2} \mathrm{a}^{-1}$. Between 75 and $825 \mathrm{~m}$ depth, mean values of $\dot{T}^{\prime}$ and $T^{\prime \prime}$ are, respectively, $8.5 \times 10^{-3} \mathrm{deg} \mathrm{m}^{-1}$ and $4.0 \times 10^{-6} \mathrm{deg} \mathrm{m}^{-1}$. The resulting mean value for the vertical velocity is -7.5 to $-15 \mathrm{~mm} \mathrm{a}^{-1}$.

This is the velocity at $450 \mathrm{~m}$ in depth, measured from the true snow surface. The ice equivalent surface is about $20 \mathrm{~m}$ lower. The vertical velocity at depth $D$ is then:

$$
w=w_{s}[1-(D-20) /(H-300)]
$$

It follows $w_{S}=-17.4$ to $-8.7 \mathrm{~mm} \mathrm{a}^{-1}$

$$
\dot{H}=A+W_{S}=20 \text { to } 28 \mathrm{~mm} \mathrm{a} a^{-1}
$$

Dome $C$ should have risen by 200 to $280 \mathrm{~m}$ during the last $10 \mathrm{ka}$. Velocities should be two to four times smaller than the balance velocities. As a consequence (which allows this fact to be discovered), the temperature profile is more linear than it would be in the steady state.

By adopting the values above for $w_{s}$, the fluctuations in $T^{\prime \prime}(z)$ can now be computed (Table II).

TABLE II. PREDICTED VALUES OF T" $(z)$

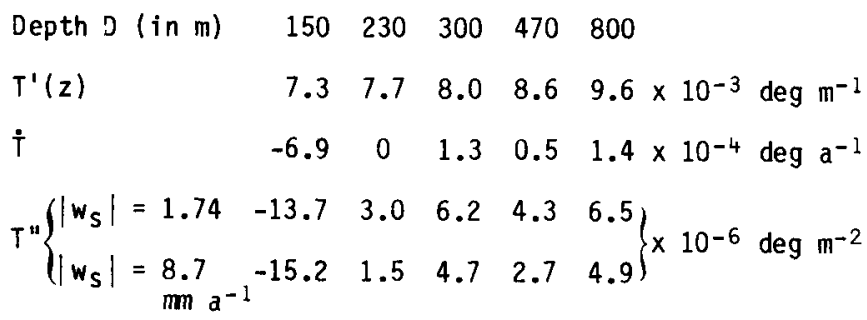

Actual fluctuations of $T "$, as estimated from Figure 2, are of the same order of magnitude as the computed ones, but the accuracy is insufficient to allow any significant check.

\section{REFERENCES}

Budd W F, Jenssen D, Radok U 1970 The extent of basal melting in Antarctica. Polarforschung: Bd 6 Jahrg 39 (1): 293-306

Budd W F, Jenssen D, Young N W 1973 Temperature and velocity interaction in the motion of ice sheets. In First Australasian conference on heat and mass transfer at Monash University, Melbourne, Australia, 1973, May 23 to May 25. Melbourne, Monash University: 17-24

Dansgaard W, Johnsen S J 1969 Comment on paper by

J. Weertman "Comparison between measured and theoretical temperature profiles of the Camp Century, Greenland, borehole". Journal of Geophysical Research 74(4): 1109-1110
Duval P 1981 Creep and fabrics of polycrystalline ice under shear and compression. Journal of GLaciology 27(95): 129-140

Hammer C U, Clausen H B, Dansgaard W, Gundestrup N, Johnsen S J, Reeh N 1978 Dating of Greenland ice cores byflow models, isotopes, volcanic debris, and continental dust. Journal of Glaciology 20(82): $3-26$

Homer D R, Glen J W 1978 The creep activation energies of ice. Journal of Glaciology 21(85): 429-444

Lliboutry L 1964 Traité de glaciologie. Tome I. Glace, neige, hydrologie nivale. Paris, Masson et Cie

Lliboutry L 1979 A critical review of analytical approximate solutions for steady state velocities and temperatures in cold ice-sheets. Zeitschrift für Gletscherkunde und Glazialgeologie 15(2): 135148

Lorius C, Donnou D 1978 Campagne en Antarctique, novembre 1977-feurier 1978. Centre National de la Recherche Scientifique. Courrier 30: 6-17

Lorius C, Mer]ivat L, Jouzel J, Pourchet M 1979 A 30,000-year isotope climatic record from Antarctic ice. Nature 280(5724): 644-648

Paterson W S B 1977 Secondary and tertiary creep of glacier ice as measured by borehole closure rates. Reviews of Geophysics and Space Physics 15(1): 47-55

Remson I, Hornberger G M, Molz F 1971 Numericaz methods in subsurface hydrology. New York etc, Wiley-Interscience

Robin $G$ de $Q 1955$ Ice movement and temperature distribution in glaciers and ice sheets. Journal of Glaciology 2(18): 523-532

Whillans I M 1978 Inland ice sheet thinning due to Holocene warmth. Science 201(4360): 1014-1016 